\title{
An Empirical Study of Effecting Watch Motivation of Korean Drama on Purchase Intention: Focused on Cosmetics in China
}

\author{
Yuan-Yuan Liu ${ }^{1}$, Ha-Kyun Kim ${ }^{2}$ \\ ${ }^{1}$ Doctoral Student of Graduate School of Information Systems, Pukyong National \\ Univ. 45, Yongso-ro, Nam-Gu, Busan, Korea, \\ ${ }^{2}$ Professor (Corresponding Author) of Division of Business, Pukyong National Univ. \\ 45, Yongso-ro, Nam-Gu. Busan, Korea, \\ 1694851404@hanmail.net, ${ }^{2}$ kimhk@pknu.ac.kr
}

\begin{abstract}
China began the Korean Wave in the late 1990s with the introduction of Korean cultural products. This study focuses on analyzing the relationship between watch motivation of Korean drama and purchase intention of cosmetics. The motivation factors for Korean drama viewing were divided into cultural curiosity, drama attractiveness, cultural similarity, relational factors, and viewing habits. Collected data were analyzed using SPSS 22.0 as basic statistics and Smart PLS 2.0 (Partial Least Squared) using structural equations. The results of the empirical analysis of this study are summarized as follows. First, the motive for watching Korean dramas (cultural curiosity, drama attractiveness, cultural similarity, relational factors, and viewing habits) had a significant effect on Korean attractiveness.
\end{abstract}

Keywords: Cultural curiosity, Drama attractiveness, Cultural similarity, Relational factors, Viewing habits

\section{Introduction}

Since the 1980s, global trends have continued to accelerate the globalization of culture. Since the 1990s, Korean cultural products have been spreading rapidly in Asia. Now, not only in Asia, but in the United States, Europe and South America, even in Asia and the Middle East. Korean singer Psy's Gang-nam style ranked second in the 2012 US Billboard chart. Gang-nam style music video views exceeded 2.8 billion views on Youtube site.

Therefore, this study is aimed at Chinese viewers who live in China and have experience of watching Korean dramas. The purpose of this study is as follows. First, this study empirically analyzes whether The watch motivation of Korean drama has a significant effect on Korean attractiveness. Second, this paper empirically analyzes whether Korean attractiveness has a significant influence on the purchase intention of Korean cosmetics.

\section{Related Research}

Chinese viewers can get new information about Korean culture by watching Korean dramas and form a positive image of Korea [1]. By discovering strong cultural proximity in terms of

Article history:

Received (July 9, 2019), Review Result (September 15, 2019), Accepted (November 4, 2019) 
material, presence, and content of Korean and Chinese dramas, Chinese viewers preferred Korean dramas because of their cultural familiarity and proximity to traditional values [2].

Purchase intention refers to the consumer's willingness to purchase something, and understanding the purchase intention is also important as a link between understanding the consumer's buying behavior and buying attitude and purchasing behavior [3]. It suggests that the purchase intention is a subjective psychological state in which the consumer wants to perform a direct action based on a comprehensive evaluation of a specific object [4]

\section{Research design}

\subsection{Research model}

The purpose of this study is to investigate the influence of Korean TV dramas on Korean attractiveness and purchase intention. Find out what are the main motivations for Chinese people to watch Korean dramas [5]. Based on the analysis results, this study suggests implications by inducing the intention to visit Korea and the purchase of cosmetics about Korean dramas of city halls in China. In order to achieve this goal, the research model is shown in [Figure 1].

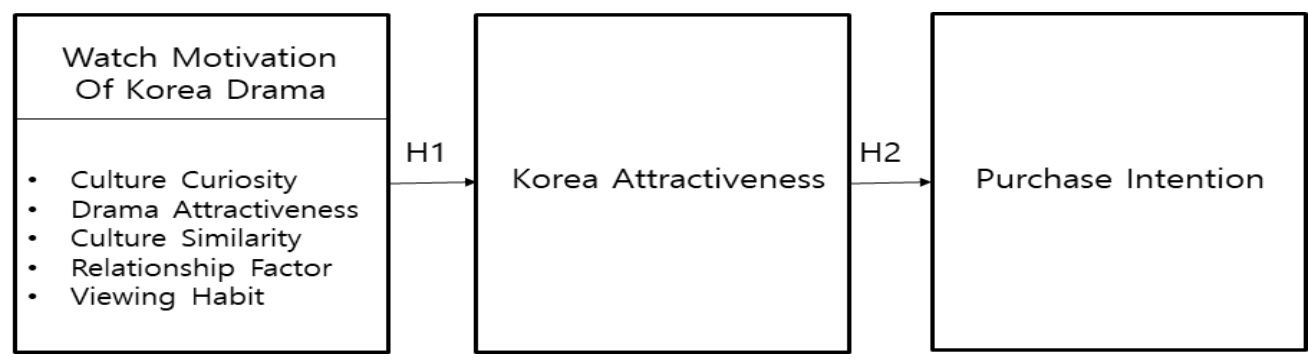

Figure 1. Research Model

\subsection{Research hypothesis}

\subsubsection{Hypothesis on watch motivation of Korea drama and Korean attractiveness:}

The main motives affecting the Chinese people's motivation to watch Korean dramas were categorized into five categories: cultural curiosity, drama attractiveness, cultural similarity, relational factors, and viewing habits. Viewers who watch Korean dramas are watching dramas to satisfy their various needs, and it can be said that there are various viewing motivations for individuals [6]. Therefore, this study established the following hypothesis.

Hypothesis 1: Watch motivation of Korea drama have a significant effect on Korean attractiveness.

H1-1: Cultural curiosity have a significant impact on Korean attractiveness.

H1-2: Drama attractiveness have a significant impact on Korean attractiveness.

H1-3: Cultural similarities have a significant impact on Korean attractiveness.

H1-4: Relational factors have a significant effect on Korean attractiveness.

H1-5: Viewing habits have a significant effect on Korean attractiveness. 


\subsubsection{Hypothesis on Korean attractiveness and Purchase Intention:}

Under the influence of the Korean wave, Chinese consumers improved their image of Korean cosmetics and evaluated their quality. Korean cosmetic companies attempted to enter China with a good opportunity to enter the Chinese market and made good results [7]. Therefore, this study established the following hypothesis.

Hypothesis 2: Korean attractiveness has a significant impact on purchase intention.

\subsection{Empirical Analysis and Results}

\subsubsection{Characteristics of Data Collection and Sample:}

A total of 224 TV viewers who lived in China and had experience watching Korean dramas were surveyed and $45 \%$ of respondents are male and $55 \%$ are female. The majority of the respondents were 20 years old and had an education level of University graduation (63\%).

Table 1 Reliability and Consistency

\begin{tabular}{|c|c|c|c|c|c|}
\hline \multicolumn{2}{|c|}{ Variables } & $\begin{array}{c}\text { Loading } \\
\text { Factors }\end{array}$ & AVE & $\begin{array}{l}\text { Composite } \\
\text { Reliability }\end{array}$ & $\begin{array}{c}\text { Cronbach's } \\
\text { Alpha }\end{array}$ \\
\hline \multirow{3}{*}{$\begin{array}{l}\text { Cultural } \\
\text { curiosity }\end{array}$} & $\mathrm{CC} 1$ & 0.895 & \multirow{3}{*}{0.788} & \multirow{3}{*}{0.917} & \multirow{3}{*}{0.865} \\
\hline & $\mathrm{CC} 2$ & 0.883 & & & \\
\hline & $\mathrm{CC} 3$ & 0.885 & & & \\
\hline \multirow{3}{*}{$\begin{array}{c}\text { Drama } \\
\text { attractiveness }\end{array}$} & DC1 & 0.895 & \multirow{3}{*}{0.818} & \multirow{3}{*}{0.930} & \multirow{3}{*}{0.888} \\
\hline & DC2 & 0.922 & & & \\
\hline & DC3 & 0.894 & & & \\
\hline \multirow{3}{*}{$\begin{array}{c}\text { Cultural } \\
\text { similarities }\end{array}$} & CS1 & 0.909 & \multirow{3}{*}{0.804} & \multirow{3}{*}{0.925} & \multirow{3}{*}{0.878} \\
\hline & CS2 & 0.897 & & & \\
\hline & CS3 & 0.884 & & & \\
\hline \multirow{4}{*}{$\begin{array}{l}\text { Relational } \\
\text { factors }\end{array}$} & RF1 & 0.869 & \multirow{4}{*}{0.738} & \multirow{4}{*}{0.918} & \multirow{4}{*}{0.882} \\
\hline & RF2 & 0.850 & & & \\
\hline & RF3 & 0.850 & & & \\
\hline & RF4 & 0.867 & & & \\
\hline \multirow{3}{*}{$\begin{array}{l}\text { Viewing } \\
\text { habits }\end{array}$} & SH1 & 0.887 & \multirow{3}{*}{0.791} & \multirow{3}{*}{0.919} & \multirow{3}{*}{0.868} \\
\hline & $\mathrm{SH} 2$ & 0.878 & & & \\
\hline & $\mathrm{SH} 3$ & 0.903 & & & \\
\hline \multirow{3}{*}{$\begin{array}{c}\text { Korean } \\
\text { attractiveness }\end{array}$} & KF1 & 0.893 & \multirow{3}{*}{0.795} & \multirow{3}{*}{0.921} & \multirow{3}{*}{0.871} \\
\hline & KF2 & 0.901 & & & \\
\hline & KF3 & 0.881 & & & \\
\hline \multirow{4}{*}{$\begin{array}{l}\text { Purchase } \\
\text { intention }\end{array}$} & PI1 & 0.874 & \multirow{4}{*}{0.735} & \multirow{4}{*}{0.917} & \multirow{4}{*}{0.880} \\
\hline & $\mathrm{PI} 2$ & 0.851 & & & \\
\hline & $\mathrm{PI} 3$ & 0.865 & & & \\
\hline & PI4 & 0.837 & & & \\
\hline
\end{tabular}




\subsubsection{Verification of Research Model:}

In general, factor loading is 0.6 or more, configuration reliability is 0.7 or more and variance extraction index is 0.5 or more to be. The discriminant validity has no problem in discriminant validity because the variance extraction index value is greater than the longitudinal and lateral correlation coefficients.

[Table 1] and [Table 2] show that the questionnaire has reliability, concentration validity and Discriminant Validity.

Table 2 Correlation and Discriminant Validity

\begin{tabular}{|c|c|c|c|c|c|c|c|c|}
\hline Variables & AVE & CC & DC & CS & RF & SH & KF & PI \\
\hline $\begin{array}{c}\text { Cultural } \\
\text { curiosity }\end{array}$ & 0.788 & 0.887 & & & & & & \\
\hline $\begin{array}{c}\text { Drama } \\
\text { attractiveness }\end{array}$ & 0.818 & 0.858 & 0.904 & & & & & \\
\hline $\begin{array}{c}\text { Cultural } \\
\text { similarities }\end{array}$ & 0.804 & 0.851 & 0,834 & 0.896 & & & & \\
\hline $\begin{array}{c}\text { Relational } \\
\text { factors }\end{array}$ & 0.738 & 0.819 & 0.835 & 0.829 & 0.859 & & 0.891 & \\
\hline $\begin{array}{c}\text { Viewing habits } \\
\text { Korean } \\
\text { attractiveness }\end{array}$ & 0.791 & 0.852 & 0.833 & 0.862 & 0.810 & 0.889 & & \\
\hline $\begin{array}{c}\text { Purchase } \\
\text { intention }\end{array}$ & 0.735 & 0.768 & 0.766 & 0.753 & 0.836 & 0.734 & 0.762 & 0,857 \\
\hline
\end{tabular}

\subsubsection{Verification of Research Model:}

Smart PLS 2.0 was used to derive the path and decision coefficient $\left(\mathrm{R}^{2}\right)$ results between the variables in the research model. Smart PLS 2.0 has the advantage of being able to analyze with a small number of samples because it can be analyzed with 10 times the number of samples to measure latent variables. Cohen described goodness as 'high' when the $\mathrm{R}^{2}$ value was 0.26 or more. If the goodness of fit is $0.26 \sim 0.13$, it can be marked as 'medium', and the goodness of fit is less than 0.13 as 'low' [8]. Korea's attractiveness (0.840) and purchase intentions $(0.581)$ were 'high'.

In hypothesis H1-1, cultural curiosity and Korean attractiveness $(\beta=0.245, t=6.031, p$ $<0.05)$ were found to have a significant effect.

In hypothesis H1-2, drama attractiveness and Korean attractiveness $(\beta=0.210, t=5.111, p$ $<0.05)$ had a significant effect. The more you watch Korean dramas, the more you like Korea.

The cultural similarity of hypothesis H1-3 $(\beta=0.145, \mathrm{t}=4.574, \mathrm{p}<0.05)$ was found to have a significant effect.

The relational factors of hypothesis $\mathrm{H} 1-4$ and the Korean attractiveness $(\beta=0.209, \mathrm{t}=5.632$, $\mathrm{p}<0.05$ ) were found to have a significant effect.

The viewing habits of hypothesis $1-5$ and the Korean attractiveness $(\beta=0.172, t=4.162, p$ $<0.05)$ were found to have a significant effect. 
The Korean attractiveness of hypothesis $\mathrm{H} 2$ and the purchase intention of Korean cosmetics $(\beta=0.762, \mathrm{t}=35.373, \mathrm{p}<0.05)$ had a significant effect.

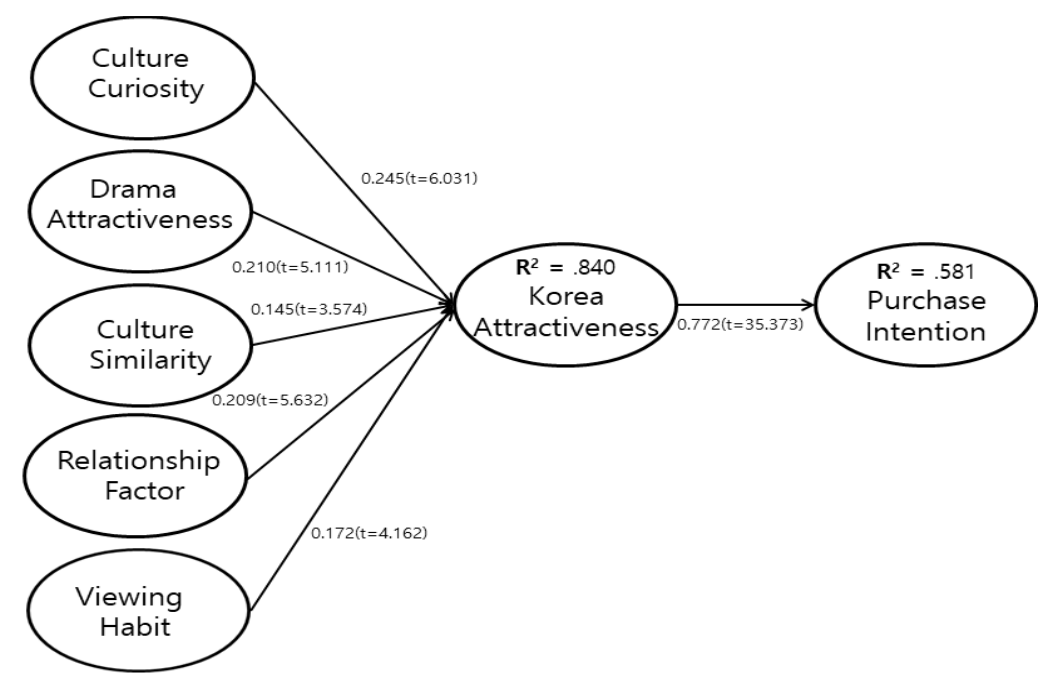

Figure 2. The Results of Research Model

\section{Conclusion}

The purpose of this study is to identify the watch motivations for Korean dramas that reflect the various needs and needs of Chinese tourists. In the existing research, we want to establish the factors of viewing motives, to understand what viewers like in Korea, and to examine how Korean attractiveness influences on intention to purchase cosmetics. First of all, the cultural curiosity of watching Korean dramas is the question related to the facilities where people want to know Korean culture, Korean life, and information. Second, among the five factors of Korean drama viewing motives, the drama's attractiveness of Korean drama viewing motives is included. Third, cultural similarity factors of Korean drama viewing motivation include drama contents similar to Chinese traditions, drama contents similar to Chinese culture, and drama setting similar to Chinese reality. Fourth, the relational factors of Korean drama watching motivation include the desire to visit Korea and to live in Korea. Fifth, the viewing habits of watching Korean dramas include the habitual viewing of Korean dramas.

In Hypothesis 1, five factors of watch motivation for Korean dramas (cultural curiosity, drama attractiveness, cultural similarity, relational factors, and viewing habits) all showed a positive influence on the attractiveness. These results suggest that the motivation factors for watching Korean dramas are all important factors in order to increase the likelihood of Chinese viewers watching Korean dramas. Therefore, it is an important factor influencing Korean viewership for Chinese viewers. In Hypothesis 2, Korean attractiveness has a positive effect on the purchase intention of cosmetics. As a result, it can be seen that the high likelihood of Korea has a direct influence on the intention of purchase of Korean cosmetics among Chinese viewers who use Korean dramas, and the goodwill also positively affects the intention of purchasing cosmetics.

\section{References}

[1] R. E. Miles, C. C. Snow and J. Preffer, "Organization-Environment: Concepts and Issue, Industrial Relation ", Vol 13, No 3, pp. 244-264 (1974). DOI: 10.1111/j.1468-232X.1974.tb00581.x 
[2] J, Kim, "A Study on the Effect of Korean Wave Drama in China, Master's Degree from Chung-Ang University " (2014).

[3] B, Park and O. Park, "Consumer behavior, Seoul: Booknet ", (1990).

[4] N. Park and W. Kim, "A Study on the Effect of Perceived Web Service Quality on Corporate Image Construction and Purchase Intention ", Consumer Studies, Vol 12, No 3, pp. 1-27 (2001).

[5] Y. Cha, "Impact of the Korean Wave on Korean Tourism-Focused on Chinese Tourists, Master's Thesis ", College of Public Policy, Seogang University (2004).

[6] S. Cho, "The Effect of Korean Wave Perception on Korean Products Purchase and National Image in Chinese Market ", Consumer Studies, Vol 17, No 3, pp. 96-106 (2006).

[7] K. Park and G. Song, "A Study on Emotional Identities in Television Dramas-Focused on the Correlation between Homogeneity, Motivation of Viewing, and Audience Satisfaction ", Korea Broadcasting Journal, Vol 23, No 2, pp. 233-275 (2009).

[8] J. Cohen, "Statistical Power Analysis for the Behavioral Science (2nd ed.) ", Hillside, Newjersey: Lawrence Erlbaum, (1988) 